\title{
Role of laparoscopic antireflux surgery in the management of chronic GERD symptoms
}

M Anvari. Role of laparoscopic antireflux surgery in the management of chronic GERD symptoms. Can J Gastroenterol 1999;13(9):761-764. Since the application of minimally invasive techniques to antireflux surgery eight years ago, there has been a rapid increase in the use of laparoscopic antireflux surgery. It is increasingly used as an alternative to long term medical therapy with proton pump inhibitors. The factors responsible for the rapid popularity of this procedure are reviewed, and the choice of techniques, current indications and available literature on the outcomes of these procedures are discussed.

Key Words: Gastroesophageal reflux disease; Laparoscopic antireflux surgery

\begin{abstract}
Rôle de la chirurgie laparoscopique antireflux dans la prise en charge des symptômes chroniques de reflux gastrooesophagien

RÉSUMÉ : Depuis l'application de techniques peu sanglantes à la chirurgie antireflux ces huit dernières années, l'utilisation de la chirurgie laparoscopique antireflux a rapidement augmenté. Cette technique sert de plus en plus de solution de remplacement au traitement médical à long terme faisant appel à des inhibiteurs de la pompe à protons. Les facteurs qui ont contribué à l'adoption rapide de cette technique sont passés en revue, et le choix des techniques, les indications actuelles, de même que la littérature disponible sur les résultats de ces interventions, sont discutés.
\end{abstract}

\section{Mehran Anvari MB BS PhD FRCSC FACS}

$\mathrm{S}_{\mathrm{s}}$ ince the first description of laparoscopic antireflux surgery in 1991 (1), there has been a rapid increase in its use and popularity $(2,3)$. The reasons for the rapid adoption of these procedures primarily have been their early success in controlling reflux symptoms coupled with significant lowering of hospital stay, postoperative morbidity and pain, and rapid recovery following surgery (4). The wide use of proton pump inhibitors to control chronic gastroesophageal symptoms has also contributed to the increasing use of laparoscopic fundoplication (4-6). The near complete relief of symptoms offered by proton pump inhibitors and the high recurrence rate of symptoms once patients stop these medications have resulted in a large population of patients on maintenance therapy.

Many younger patients on long term proton pump inhibitors are seeking alternatives and are being referred for laparoscopic fundoplication (4). The choice of surgery over long term medication has become more common in the era of laparoscopic surgery because patients are more accepting of an operation without a large incision and long recovery period, even if the surgery still carries some risks. The proportion of patients who choose surgery even though their symptoms are well controlled on maintenance therapy is reported by some of the larger centres to be close to one-third of those undergoing laparoscopic fundoplication (4).

Despite its early success, there are still some significant issues with respect to laparoscopic antireflux surgery that should be addressed further. One issue is who should perform the surgery. Increasing evidence suggests that the surgeon's skill and experience have a direct impact on the morbidity and success of the procedure $(7,8)$. Laparo-

This mini-review was prepared from a presentation made at a meeting entitled "Update gastroesophageal disease", held at the meeting of the Royal College of Physicians and Surgeons of Canada, in Toronto, September 1998

Department of Surgery, St Joseph's Hospital, McMaster University, Hamilton, Ontario

Correspondence and reprints: Dr M Anvari, St Joseph's Hospital, 50 Charlton Avenue East, Hamilton, Ontario L8N 4A6.

Telephone 905-522-2951, fax 905-521-6113, e-mail anvari@mcmaster.ca 
scopic antireflux surgery requires a high degree of twohanded laparoscopic skill and has a longer learning curve than simpler laparoscopic procedures such as laparoscopic cholecystectomy or appendectomy (9). Many experts believe that any surgeon performing laparoscopic antireflux surgery not only should be trained and familiar with all aspects of management of such patients, but also needs to do a minimum of 12 procedures a year to maintain the necessary level of skill.

Selection and preparation of patients also contribute significantly to the success of surgery. The presence of significant esophagitis in the era of proton pump therapy is rare; thus, objective evaluation of acid reflux by $24 \mathrm{~h} \mathrm{pH}$ testing and an assessment of esophageal motor function by esophageal manometry are necessary parts of the preoperative workup of a potential surgical candidate (3). Furthermore, ongoing follow-up of patients after surgery is essential because it allows each surgeon to evaluate his or her results against the expected published norms (7).

Another criticism against laparoscopic antireflux surgery is the lack of long term follow-up data. Although some four- and five-year follow-up data are being presented or published (10), there will still be a number of years before convincing long term data on large numbers of patients are available. However, that laparoscopic antireflux surgery only differs from its open counterpart in its method of access to the hiatus and not in the technical details should suggest that the long term outcome of these procedures should not be significantly different from their open counterpart with well established long term records.

\section{CHOICE OF DIFFERENT TECHNIQUES}

A number of different antireflux procedures are available and are in use. The most common procedures used are laparoscopic Nissen fundoplication (1) and laparoscopic Toupet fundoplication (11). A number of other techniques such as laparoscopic Hill repair (12) or Watson repair (13) are offered by some centres but are not in wide use.

Laparoscopic Nissen fundoplication is the technique of choice for most patients. The long term follow-up of patients after open Nissen fundoplication has shown that, when performed by a skilled surgeon, it has a 10 -year success rate of $85 \%$ to $90 \%(14,15)$. Coupled with the evidence that the procedure is well tolerated even in patients with esophageal motor abnormality $(7,16)$ and that it is associated with a low rate of unwanted postoperative symptoms, the success rate has made laparoscopic Nissen fundoplication the primary choice for antireflux surgery by most surgeons. It remains the most popular antireflux technique in the era of laparoscopic surgery. Performing the procedure laparoscopically provides for a better visualization of the operative field and can reduce not only the operating time, but also the risk of intraoperative complications (7). There are a number of small technical details with respect to performing laparoscopic Nissen fundoplication, such as whether to divide short gastric vessels rou- tinely, which is still debated and arouses interest among surgeons but probably has no real impact on the long term outcome of the operation (17). What does, however, appear to have an impact is the length and looseness of the wrap. There is increasing evidence that very short (less then $2 \mathrm{~cm}$ ) or very loose (56 to 60 French) wraps may be associated with a higher recurrence rate (7). To minimize the possibility of recurrence and prevent unnecessary postoperative complications of dysphagia and gas-bloat syndrome, it has been demonstrated that gauging the tightness of the wrap based on the status of esophageal motor function assessed by preoperative manometry provides excellent results (4).

Laparoscopic Toupet fundoplication, in which a partial wrapping of the fundus around the distal esophagus is constructed, is regarded by some surgeons as the technique of choice in patients with abnormal esophageal motility (18). Evidence in the literature shows that the Toupet procedure is associated with lower postoperative dysphagia and gas-bloat rates than is Nissen fundoplication, at least in the early postoperative phase (18). Studies also show that the increase in the high pressure zone at the lower esophageal sphincter region is significantly less after Toupet fundoplication than after Nissen fundoplication (19) and has been suggested as the reason for the higher recurrence rate compared with Laparoscopic Nissen fundoplication. Even the most ardent proponents of Toupet fundoplication suggest that the procedure should be preserved for patients with severe esophageal dysmotility or with mild reflux disease unable to take medication (20).

\section{LONG TERM COMPLICATIONS OF ANTIREFLUX SURGERY}

The most feared complication of antireflux surgery is dysphagia. The incidence of postoperative dysphagia in the immediate period after surgery remains high, but for most patients the symptoms completely subside by six to eight weeks after surgery (21). The incidence of long term dysphagia after laparoscopic fundoplication (Nissen and Toupet), however, is low (less than 3\%). Three recent studies have found that the symptom of dysphagia improved after laparoscopic antireflux surgery in the majority of patients $(7,17,21)$. These results are similar to those reported with the open fundoplication (22). A number of factors, including an improvement in esophageal motor function, have been suggested as possible reasons $(22,23)$ but have not been investigated adequately. Patients with normal esophageal motility, or mild or moderate esophageal dysmotility are recommended to have laparoscopic Nissen fundoplication, while patients with severe esophageal motor dysfunction are considered for a very loose Nissen or a Toupet fundoplication. Those in the latter group, who may already experience dysphagia, however, risk the possibility of facing significant dysphagia for solids after surgery (21). Thus, the decision to operate on these patients should be made jointly by the surgeon, the patient and the referring gastroenterologist. In most instances, surgery in 
these patients is a last resort for complications of chronic gastroesophageal reflux disease (GERD) (most often respiratory complication) that have not responded to high doses of proton pump inhibitors.

Another significant complication of laparoscopic antireflux surgery is gas-bloat syndrome, which is reported in $1 \%$ to $3 \%$ of cases $(4,7)$. Although many patients experience some difficulty with belching and may experience bloating after a large or rapidly ingested meal, very few develop the severe symptoms associated with gas-bloat syndrome. These patients may be treated with proton pump inhibitors or dilation of the wrap, but some may require complete reversal of the wrap if the symptoms persist. The exact etiology of gas-bloat syndrome is poorly understood. Suggestions that it may be due to a tight or a long wrap have not been supported in the literature. Recent studies have suggested that this may be due to abnormal central processing of vagal signals, but this requires further evaluation (24).

One of the most common cause of reoperation after laparoscopic antireflux surgery is development of paraesophageal herniation of the stomach through the hiatus (25). This complication is encountered after open antireflux surgery (26) but is more commonly reported after laparoscopic surgery, in part due to closer follow-up in the latter group. However, lack of adhesion formation is believed to contribute also to the development of paraesophageal hernias (27).

Several recent studies have shown that, although there is some temporary impairment of diaphragmatic function after laparoscopic fundoplication, it is substantially less than the impairment normally encountered after open antireflux surgery $(28,29)$. This has meant that many patients with significant respiratory compromise who previously were refused open surgery can now undergo laparoscopic antireflux surgery without significant risk of morbidity or mortality.

Overall, the rate of complications after laparoscopic fundoplication in an appropriately selected patient and when performed by an experienced surgeon remains low. This has certainly been a significant factor in the rapid adoption of this technique by surgeons and its popularity among referring physicians and patients.

\section{REFERENCES}

1. Dallemagne B, Weerts JM, Jehaes C, Markiewicz S, Lombard R. Laparoscopic Nissen fundoplication: preliminary report. Surg Laparosc Endosc 1991;1:138-43.

2. Beck IT, Champion MC, Lemire S, et al. The Second Canadian Consensus Conference on the Treatment of Patients with Gastroesophageal Reflux Disease. Can J Gastroenterol 1997;11(Suppl B):7B-20B.

3. Poulin EC, Schlachta CM, Mamazza J. Correcting reflux laparoscopically. Can J Gastroenterol 1998;12:327-32.

4. Anvari M, Allen C. Laparoscopic Nissen fundoplication: two year comprehensive follow-up of a technique of minimal paraesophageal dissection. Ann Surg 1998;1:24-32.

5. Anvari M, Allen C, Borm A. Laparoscopic Nissen fundoplication: an alternative to long-term omeprazole? Br J Surg 1995;82:938-42.

6. McKenzie D, Grayson T, Polk H. The impact of omeprazole and

\section{FOLLOW-UP DATA AVAILABLE}

The best follow-up data published extend for the first two to five years after antireflux surgery $(4,10,20)$. These data suggest that laparoscopic fundoplication increases the high pressure zone at the lower esophageal sphincter and remains an effective antireflux barrier in approximately $95 \%$ of patients over this period. However, long term (10 to 20 years) data are needed to establish completely the long term efficacy of this treatment modality.

Laparoscopic fundoplication has also been shown to be effective treatment in patients with respiratory complications of GERD, particularly chronic cough (30) and pulmonary fibrosis secondary to repeat aspiration pneumonia (31), who often do not respond adequately to medical therapy.

The hospital cost of laparoscopic fundoplication in Canada is about $\$ 2500$ to $\$ 3000$ (32). Even with the addition of time lost from work after surgery, it is likely that this modality is more cost effective in patients who require proton pump therapy for longer than three years.

\section{SUMMARY}

The recent adoption of laparoscopic techniques has significantly reduced the hospital stay and postoperative recovery after antireflux surgery. Early results suggest that this surgery remains effective in the majority ( $90 \%$ or more) of patients followed for up to five years. Laparoscopic Nissen fundoplication is the technique of choice for most surgeons. Appropriate selection of patients with full preoperative workup, including $24 \mathrm{~h} \mathrm{pH}$ testing, esophageal manometry and endoscopy, is recommended. The complication rate after this surgery is low and is in part related to the skill and experience of the surgeon.

Laparoscopic antireflux surgery has the potential to offer a significant clinical alternative to a large number of reflux patients on maintenance therapy with proton pump inhibitors. It should be considered in all patients who require long term therapy and who do not have significant surgical risk factors.

The last Canadian Consensus conference on GERD recommended a prospective randomized trial to assess the cost effectiveness of laparoscopic fundoplication in the treatment of chronic GERD symptoms in patients on maintenance medical therapy.

laparoscopy upon hiatal hernia and reflux esophagitis. J Am Coll Surg 1996;183:413-8.

7. Anvari M. Complications of laparoscopic Nissen fundoplication. Semin Laparosc Surg 1997;4:154-61.

8. Watson DI, Jamieson GG. Antireflux surgery in the laparoscopic era. Br J Surg 1998;85:1173-84.

9. Gotley DC, Smithers BM, Rhodes M, Menzies B, Branicki FJ, Nathanson L. Laparoscopic Nissen fundoplication - 200 consecutive cases. Gut 1996;38:487-91.

10. Dallemagne B, Weerts JM, Jeahes C, Markiewicz S. Results of laparoscopic Nissen fundoplication. Hepatogastroenterology 1998;45:1338-43.

11. McKernan BJ, Champion JK. Laparoscopic antireflux surgery. Am Surg 1995;61:530-6. 
12. Aye RW, Mazza DE, Hill LD. Laparoscopic Hill repair in patients with abnormal motility. Am J Surg 1997;173:379-82.

13. Watson A, Spychal RT, Brown MG, et al. Laparoscopic "physiological" antireflux procedure: Preliminary results of a prospective symptomatic and objective study. Br J Surg 1995;82:651-6.

14. Luostarinen M, Isolauri J, Laitinen J, et al. Fate of Nissen fundoplication after 20 years: A clinical, endoscopical, and functional analysis. Gut 1993;34:1015-20.

15. Grande L, Toledo-Pimentel V, Manterola C, et al. Value of Nissen fundoplication in patients with gastro-esophageal reflux judged by long-term symptom control. Br J Surg 1994;81:548-50.

16. Beckingham IJ, Cariem AK, Bornman PC, Callanan MD, Louw JA. Oesophageal dysmotility is not associated with poor outcome after laparoscopic Nissen fundoplication. Br J Surg 1998;85:1290-3.

17. Watson DI, Pike GK, Baigrie RJ, et al. Prospective double-blind randomized trial of laparoscopic Nissen fundoplication with division and without division of short gastric vessels. Ann Surg 1997;226:642-52.

18. Bell RCW, Hanna P, Sabel J, Hruza D. Clinical and manometric results of laparoscopic partial (Toupet) and complete (Rosetti -

Nissen) fundoplication. Surg Endosc 1996;10:724-8.

19. Freys SM, Fuchs KH, Heimbucher J, Thiede A. Tailored augmentation of the lower esophageal sphincter in experimental antireflux operations. Surg Endosc 1997;11:1183-8.

20. Jobe BA, Wallace J, Hansen PD, Swanstrom LL. Evaluation of laparoscopic Toupet fundoplication as a primary repair for all patients with medically resistant gastroesophageal reflux. Surg Endosc 1997;11:1080-3.

21. Anvari M, Allen C. Prospective evaluation of dysphagia before and after laparoscopic Nissen fundoplication without routine division of the short gastrics. Surg Laparosc Endosc 1996;6:424-9.

22. Hunter JG, Trus TL, Branum GD, Waring JP, Wood WC. A physiologic approach to laparoscopic fundoplication for gastroesophageal reflux disease. Ann Surg 1996;223:673-87.

23. Gill RC, Bowes KL, Murphy PD, Kingma YJ. Esophageal motor abnormalities in gastroesophageal reflux and the effects of fundoplication. Gastroenterology 1986;91:364-9.

24. Hollerbach S, Bajwa A, Fitzpatrick D, et al. The autonomic response to esophageal stimulation is enhanced by the involvement of cortical pathways. Gastroenterology 1997;112:A748. (Abst)

25. Watson DI, Jamieson GG, Devitt PG, Mitchell PC, Game PA. Paraoesophageal hiatus hernia: an important complication of laparoscopic Nissen fundoplication. Br J Surg 1995;82:521-3.

26. Leonardi HK, Crozier RE, Ellis FH. Reoperation for complications of Nissen fundoplication. J Thorac Cardiovasc Surg 1981;81:50-6.

27. Krahenbuhl L, Schafer M, Kuzinkovas V, Renzulli P, Baer HU, Buchler MW. Experimental study of adhesion formation in open and laparoscopic fundoplication. Br J Surg 1998;85:826-30.

28. Olsen MF, Josefson K, Dalenback J, Lundell L, Lonroth H. Respiratory function after laparoscopic and open fundoplication. Eur J Surg 1997;163:667-72.

29. Anvari M, Allen C. Prospective evaluation of dysphagia before and after laparoscopic Nissen fundoplication without routine division of the short gastrics. Surg Laparosc Endosc 1996;6:424-9.

30. Allen C, Anvari M. Reflux-related cough and the effects of laparoscopic Nissen fundoplication. Thorax 1998;53:963-8.

31. Anvari M, Allen C, Moran LA. Immediate and delayed effects of laparoscopic Nissen fundoplication on pulmonary function. Surg Endoscopy 1996; 10:1171-5.

32. Anvari M. Is laparoscopic Nissen fundoplication a logical alternative to long term therapy for GERD? In: Giuli R, ed. The Esophagogastric Junction (O.E.S.O.). Paris: John Libbey Eurotest, 1998:861-3. 


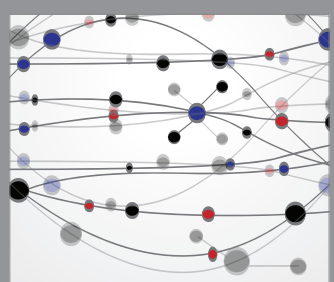

The Scientific World Journal
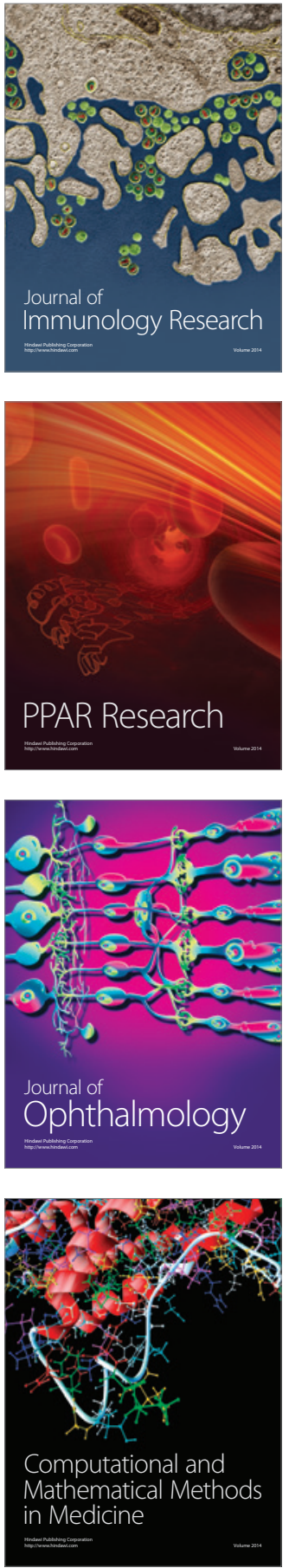

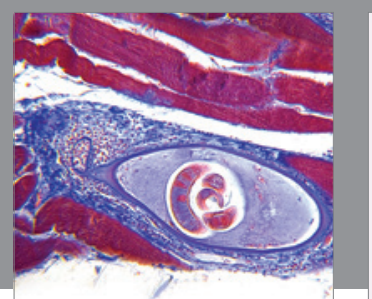

Gastroenterology Research and Practice

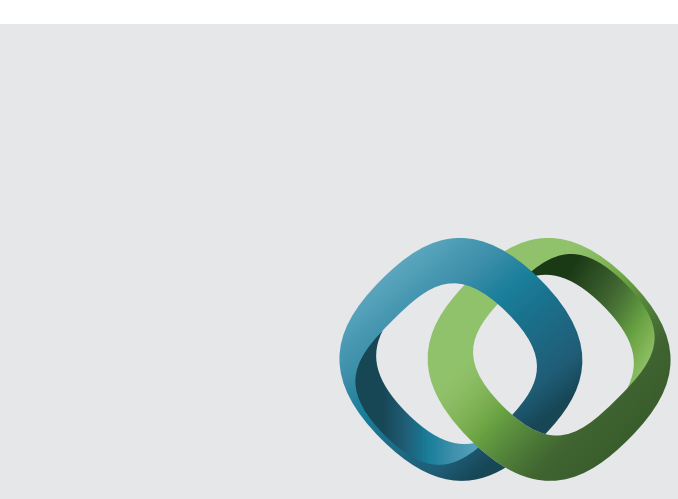

\section{Hindawi}

Submit your manuscripts at

http://www.hindawi.com
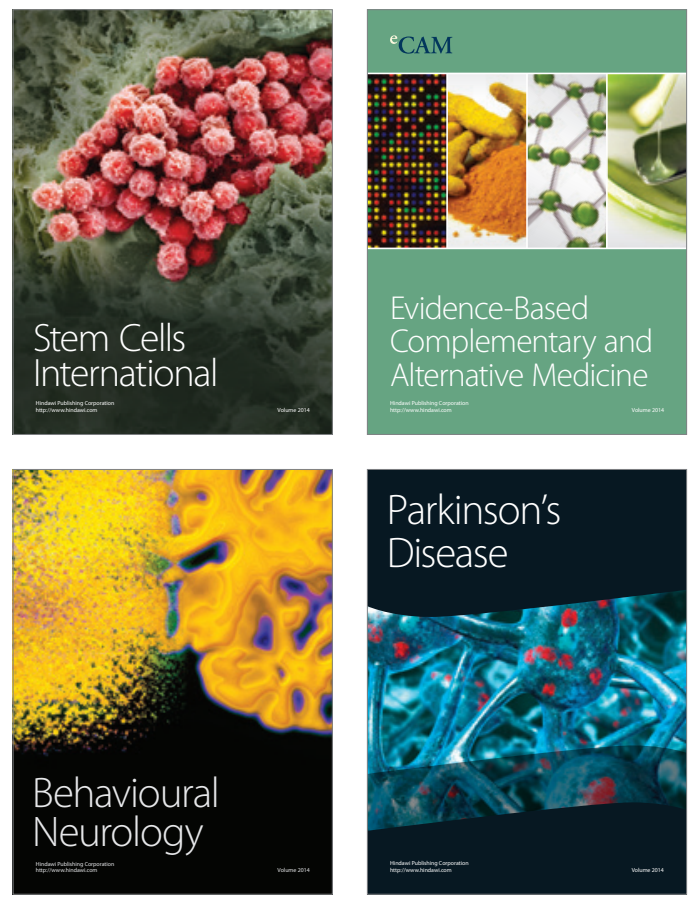
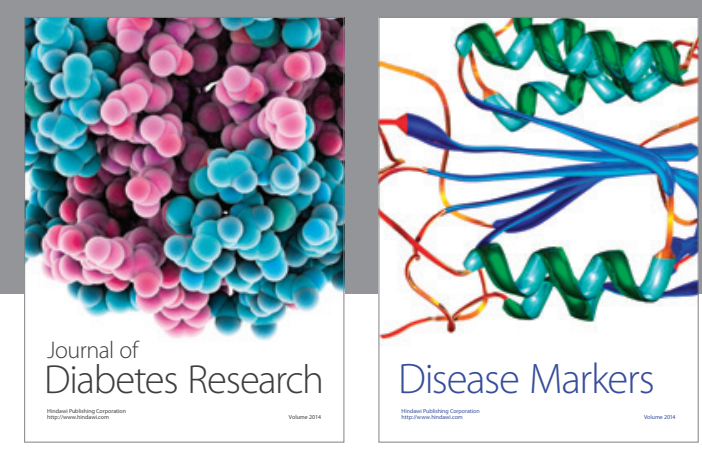

Disease Markers
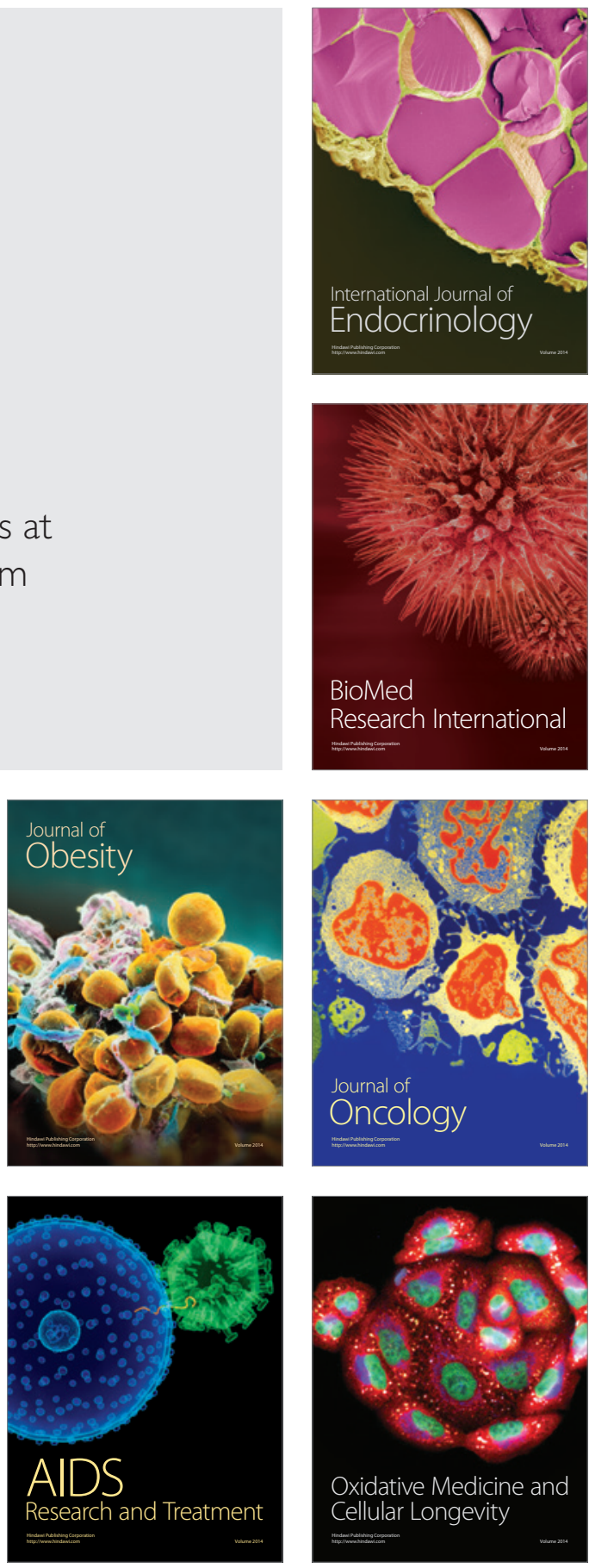